\title{
Marketing digital como ferramenta estratégica e as oportunidades nas redes sociais
}

\author{
Digital marketing as a strategic tool and opportunities in social networks
}

\section{Vanessa Bolico da Silva 1}

\author{
1 Email \\ vanessab-silva@hotmail.com \\ FUNORTE
}

\begin{abstract}
Resumo
As influências do macroambiente sobre o marketing são capazes de interferir profundamente nas organizações. Assim, o fator tecnológico impacta fortemente sobre os negócios, colocando para as empresas a necessidade de promoverem mudanças na forma de se relacionar com os seus consumidores, divulgar seus produtos e serviços, alterando até mesmo a forma de venda. Os avanços da informática levaram à produção de vários dispositivos de comunicação e informação e ao desenvolvimento da internet, rede de computadores, que se popularizou. A partir de então, as organizações tiveram a necessidade de incluir as plataformas e os dispositivos digitais no planejamento de marketing. Nesse sentido, o objetivo deste trabalho é estudar as estratégias de marketing em plataformas digitais e analisar sua aplicação pelas Lojas Renner. Estas fazem investimento significativo dos seus recursos para realização do marketing em meios tradicionais e nas plataformas e dispositivos digitais, sendo que obtém retorno em suas estratégias, pois alcança o engajamento e a participação do consumidor, nas ações desenvolvidas na internet, as quais certamente se refletem nos resultados financeiros da empresa.
\end{abstract}

Palavras-Chave: Gestão Estratégica; Marketing digital; Redes sociais.

\begin{abstract}
Macro environment influences on marketing are able to interfere deeply in organizations. Thus, the technological factor has a heavily impact on business, placing enterprises the need of making some changes dealing with their costumers, advertising their products and services, even changing how to sell it. The advances in computer technology have led to the production of several communication and information devices and internet development, computer network, which became popular. Since then, organizations had the need to include platforms and digital devices on marketing plans. Accordingly, the aim of this work is to study marketing strategies in platforms and digital devices and analyze their application by Renner store. These are significant investment of their resources to perform marketing in traditional ways and in platforms and digital devices, getting some feedback on their strategies since it reaches costumer engagement and participation in activities developed on the internet, which will certainly reflect in the company's financial results.
\end{abstract}

Keywords: Strategic management; Digital marketing; Social networks. 


\section{INTRODUÇÃO}

Para o bom rendimento das organizações, é fundamental atentar para as estratégias de marketing. Nesse sentido, entre as várias questões que precisam ser consideradas para a realização do planejamento de marketing, destaca-se o ambiente, o qual inclui as perspetivas micro e macro, de modo que as organizações devem considerar as influências do micro e do macroambiente. Relativo ao macro, a área de marketing deve estar atenta às forças que a afetam, entre as quais se inclui o fator tecnológico. Sendo assim, é importante para o marketing acompanhar o desenvolvimento de novas tecnologias que surgem em diversos campos, como a área da informação e da comunicação, por exemplo, a fim de estar a par das inovações que possam afetar os negócios.

A eletrônica e a informática promoveram profundas transformações na sociedade, mudanças que também possibilitaram ao marketing a implementação de novas ferramentas e técnicas, em seus estudos, pesquisas e formas de trabalhar o relacionamento com o consumidor. Assim, o estudo das estratégias de marketing em plataformas e tecnologias digitais, como sites, blogs, sites de busca, sites de relacionamento social, aplicativos e dispositivos é relevante, pois isso impactou e transformou a sociedade, o mercado e os consumidores. Para se relacionar com seu público-alvo, o marketing necessita entender e utilizar plataformas e tecnologias digitais.

Este artigo tem, pois, como objetivo refletir sobre essa realidade, de modo que aborda, primeiramente, a definição de marketing, seu planejamento e a formulação de estratégias. Em seguida, centra-se no que vem a ser a internet e seus usos, as diferentes plataformas e os dispositivos desenvolvidos para a utilização da rede, com o intuito de compreender sua relação com o marketing. Por fim, busca entender como são formuladas estratégias de marketing para plataformas digitais, ao estudar o caso das Lojas Renner, empresa que utiliza esses recursos digitais no marketing da organização, para construir seu relacionamento com seu público-alvo. 


\title{
FUNDAMENTAÇÃO TEÓRICA
}

\author{
Marketing: definição e aplicação
}

Conforme Philip Kotler e Kevin Lane Keller (2006), o mercado já foi definido como o local físico partilhado por compradores e vendedores, para negociar produtos. Em sua etimologia, observa Siqueira (2005), o mercado seria um centro de comércio ou mesmo uma povoação em que existe uma movimentação comercial de porte.

Kotler (2006) afirma que, comumente, a área de marketing utiliza o termo mercado para definir determinados grupos de clientes. Nesse sentido, os vendedores são compreendidos como um setor e os consumidores, como mercado. Atualmente, segundo Kotler (2006), a definição de mercado também abarca questões relativas ao local e à disposição espacial. $\mathrm{O}$ local de mercado ou marketplace é relativo ao espaço físico, como, por exemplo, um shopping, enquanto o marketspace ou mercado digital é o lugar digital, que pode ser um site de uma loja na internet.

Atender aos desejos e às necessidades do mercado, definido para um produto ou serviço, é função do marketing. Cobra (2009) observa que os profissionais da área tomam decisões considerando os desejos e as necessidades dos consumidores. Conforme Kotler e Keller (2006), marketing é a técnica que tem por objetivo a identificação e a satisfação das necessidades sociais e que supriria as necessidades lucrativamente. Kotler (2006) argumenta que o objetivo do marketing seria conhecer e entender o cliente tão profundamente, que o produto ou serviço adequado autopromova a sua venda. Cobra (2009) argumenta que o plano de marketing tem como ponto de partida o plano corporativo. O planejamento é a fase inicial da administração dos esforços de marketing e abarca várias atividades, observa Madruga (2011), como a análise de oportunidades, a seleção de mercados-alvo, a definição de estratégias e o controle da sua execução.

O estudo do ambiente observa Gabriel (2010), em Marketing na Era Digital, é uma das questões mais relevantes do planejamento de marketing ou de uma estratégia. Existem dois diferentes ambientes vinculados ao marketing: o microambiente e o macro, os quais Kotler (2006) define como ambiente tarefa e ambiente geral. O microambiente é formado de forças próximas à organização, que interferem em sua capacidade de atender seu público: ambiente interno da empresa (departamentos, produtos, pessoas e outros), fornecedores, intermediários de marketing, clientes, concorrentes e públicos. Por sua vez, o macroambiente 
é formado por forças incontroláveis de maior grandeza que influenciam este campo, entre as quais podemos destacar as demográficas, as econômicas, as naturais, as tecnológicas, as políticas e as culturais.

A autora destaca que as empresas conseguem controlar seu ambiente interno e, em certa proporção, podem ter controle sobre o microambiente de marketing, de modo a transformálo, para atingir seus objetivos. Por outro lado, as empresas não possuem capacidade para exercer controle sobre o macro ambiente, pois este é constituído de acontecimentos incontroláveis. Nessa perspetiva, as empresas reagem aos acontecimentos do macro ambiente, sendo que as que apresentarem reações mais ágeis e adequadas possivelmente obterão mais vantagens competitivas. Entre as forças do macro ambiente que podem interferir em um negócio, destacam-se os fatores demográficos, que agem sobre um produto ou negócio a partir das variações da população, com base em aspetos como tamanho, concentração populacional, localização, idade, sexo e etnia. Igualmente, fatores econômicos interferem no poder de compra e na configuração de gastos do público-alvo, influenciando, com isso, os produtos e, por conseguinte, os negócios. Fatores físico-naturais agem sobre os recursos naturais utilizados como insumos. Fatores políticos são as leis, os órgãos do poder público e grupos que podem vir a agir contra a empresa, tendo repercussão sobre seus produtos ou negócios.

Por último, destaca-se o fator tecnológico, relativo especificamente às novas tecnologias, que, quando chegam ao mercado, acabam por repercutir sobre os produtos e os negócios. $\mathrm{O}$ ambiente tecnológico é o que tem propensão a apresentar transformações mais rápidas no macro ambiente em comparação aos outros. Gabriel (2010) observa que é fundamental entender as transformações no ambiente de marketing, sendo que, atualmente, um dos fatores que impulsionam tais mudanças é a disseminação das tecnologias e das plataformas digitais. As tecnologias digitais, que estão profundamente vinculadas ao cotidiano das pessoas, promoveram grandes mudanças no comportamento do consumidor.

A partir da década de 70, várias tecnologias foram criando o cenário digital que temos atualmente. Entre elas, destacam-se o fax, o PC, computador pessoal, as impressoras, a internet, o telefone celular, o GPS. Quanto à questão do acesso à internet, a banda larga promoveu importante mudança (Gabriel, 2010), pois possibilitou uma grande transformação na condição do usuário da rede que até então se caracterizava por "estar conectado" e que passou a "ser conectado". O "estar conectado", explica a autora, é relativo ao fato de que as pessoas casualmente estão conectadas à internet, o que comumente ocorria no acesso à rede 
por conexão discada durante os anos 1990. Já o "ser conectado" é relativo à outra condição, pois isso quer dizer que parte da pessoa está na rede, vivendo em simbiose com ela. Com menor custo, a banda larga de internet impulsionou a participação das pessoas na rede. Essa participação é que fomenta o crescente poder no cenário contemporâneo de marketing, tornando possível que o consumidor atue, escolha, opine, crie, influencie e consuma conforme desejar.

\section{A internet e o marketing}

Em E-commerce, Catalani et al. (2006) observam que, entre as novas tecnologias, podemos destacar a Internet, a qual segue transformando o modo como as pessoas trabalham, constroem relacionamentos e negociam. E o mais relevante aqui é que está mudando a maneira como as pessoas mantêm relacionamentos com as empresas e o próprio convívio entre empresas; e essas transformações atingem o governo também, que passa a se relacionar com a sociedade de modo diferente. Sendo assim, para organizar o uso da internet como ferramenta de marketing, as empresas necessitam conhecer a rede em profundidade, de modo a atingir bons resultados com seu uso. Gabriel (2010) argumenta que, na atualidade, o acesso à informação pode estar na tela de dispositivos móveis, os quais possibilitam interação de qualquer lugar e em qualquer tempo de modo que o consumidor assume lugar no centro das ações - processo de presença ativa em meio às marcas.

Nesse sentido, a marca torna-se responsável pela experiência recetiva que o consumidor terá, o que faz com que o planejamento do contato com o consumidor seja fruto de uma reflexão sobre a forma de utilização da mídia comumente praticada. Tradicionalmente, a propaganda, por exemplo, só ocorria quando havia propagação. Para que se propague nos dias atuais, um conteúdo necessita estar acessível ao consumidor, quando ele quiser acessar, processo que, conforme a autora, é denominado inversão do vetor de marketing. A autora destaca que o marketing de busca, o marketing em redes sociais e o marketing móbile assumem posição de destaque em qualquer estratégia de marketing, até mesmo nas estratégias de marketing de relacionamento e de marketing de experiência. O foco do marketing é a experiência do consumidor, sendo que a tecnologia que está possibilitando isso é a internet, e sua plataforma são as mídias sociais. 
O pensamento de Strauss et al., em E-marketing, segue a mesma perspetiva apresentada por Gabriel (2010). Para essa estudiosa, o marketing deve entrar no que se define como nova era de engajamento, da participação e da cocriação. O engajamento é relativo ao envolvimento do consumidor e envolver este possível cliente é conectar-se com essa pessoa emocional e cognitivamente. $\mathrm{O}$ engajamento online é semelhante à experiência proporcionada pelo marketing tradicional.

O marketing digital constrói o envolvimento com o usuário, atraindo-o para a participação em seu conteúdo ou mídia em ações como a realização de uploads de vídeos ou fotos, a postagem de comentários, vindo a ser fã da página da marca em sites de relacionamento. A cocriação acontece em situações em que os usuários auxiliam o pessoal do marketing no desenvolvimento de produtos e da publicidade. Por exemplo, isso pode ocorrer por meio de concursos que possibilitam ao consumidor criar a propaganda para a empresa.

As mudanças pelas quais a web passou foram definidas em três fases: a web 1.0, a web 2.0 e a web 3.0, dizem respeito muito mais a transformações no comportamento do usuário do que às tecnologias que possibilitaram tal transformação. A web 1.0 constitui a internet estática, em que os usuários navegam e fazem o consumo de informações. Já a web 2.0 é o meio da participação, em que os internautas fazem uso da web como plataforma para diversas formas de interação, por meio de blogs, vídeos, imagens e redes sociais. A web 3.0 é definida como a web semântica, em que, além da própria informação, o contexto e as ligações relacionadas a essa informação possibilitarão encontrar um significado que auxilie o uso da internet.

As estratégias de marketing são concebidas a partir dos 4 ps - produto, praça, preço e promoção - e até poucos anos atrás, o composto de marketing era utilizado somente com tecnologias tradicionais (Gabriel, 2010). Atualmente, os 4 ps podem ser suportados por tecnologia tradicional ou digital. Um software, como um antivírus, por exemplo, é um produto digital; o e-commerce e as redes sociais exemplificam a praça, que no caso é digital; os links patrocinados são definidos como promoção digital, pois se originam de ações de comunicação digital. O preço digital pode ser observado nos Linden Dollars do Second Life.

A autora destaca, no entanto, a necessidade de observarmos que marketing digital não existe, o que há é marketing, e seu planejamento estratégico é que definirá quais plataformas ou tecnologias serão utilizadas, se digitais ou não ou a combinação da tradicional e da digital. A multiplicidade de tecnologias e plataformas digitais disponibiliza um campo muito produtivo para vários tipos de ações de marketing, possibilita a mensuração e a sincronicidade, que são 
grandes vantagens se comparadas ao ambiente material tangível. Gabriel (2010) expõe também a necessidade de observarmos a diferença entre plataformas/tecnologias digitais e estratégias.

No meio digital, existem várias tecnologias e plataformas que podem ser suporte de estratégias de marketing. No caso das redes sociais, a plataforma seria o suporte em que se desenvolve a rede social, como, por exemplo, o Facebook, que seria uma plataforma de rede social e não a própria rede social. A rede social se desenvolve sobre as plataformas, podendo estar sobre mais de uma ao mesmo tempo, pois determinada rede social pode estar no Facebook e também no Orkut.

O mesmo acontece com o celular e outras tecnologias móveis, os quais são plataformas e não devem ser confundidas com estratégias. A forma como são utilizadas essas tecnologias define a estratégia móvel. Gabriel (2010) apresenta algumas plataformas/tecnologias digitais: páginas digitais: sites, minissites, hotsites, portais, blogs e perfis; e-mail: texto/vídeo-in-email; realidades mistas: realidade aumentada, virtualidade aumentada, realidade virtual: Seconde Life; tecnologias móbile: RFID, Mobile Tagging, SMS/MMS, Bluetooth, aplicativos, Mobile TV; plataformas digitais de redes sociais; plataformas digitais de busca: Google, Yahoo, Bing e outras; games e entretenimento digital; tecnologia inteligente de voz; vídeo/TV digital/vídeo imerso. A combinação dessas plataformas-tecnologias é a base para a conceção de estratégias digitais de marketing como: presença digital; e-mail marketing; mobile marketing; SMM (Social Media Marketing) e SMO (Social Media Optimization); SEM (Search Engine Marketing) e SEO (Search Engine Optimization).

As estratégias digitais podem relacionar vários tipos de tecnologia. Assim, uma estratégia de presença digital pode ser a combinação de site, blog e Facebook. Por sua vez, uma estratégia de mobile marketing pode ser realizada com tecnologia de realidade aumentada. Outro tipo de estratégia, a de marketing de busca, comumente utiliza uma combinação com estratégias SMM (Social Media Marketing) e Mobile Marketing (Busca Mobile). De modo a alcançar o objetivo de marketing proposto, as estratégias de marketing é que definem as ações que serão relacionadas. Pode ocorrer a utilização de tecnologias e plataformas digitais aliadas a tecnologias e plataformas tradicionais.

A presença digital origina os pontos de contato entre o público-alvo e a marca no ambiente digital, constituindo o estabelecimento das marcas no meio digital. O site de uma 
organização, por exemplo, é um ponto de presença digital, a qual se origina da existência de conteúdo digital.

Os três tipos de presença existentes são a própria, a gratuita e a paga. A presença própria caracteriza-se por conteúdos digitais da empresa, desenvolvidos e mantidos pela própria organização, tais como sites, minissites, hotsites, portais, blogs, páginas em redes sociais as quais podem ser exemplificadas por perfis e canais no LinkedIn, Twitter, YouTube, Google Profile e outros. Também se incluem na presença própria, o envio de e-mail marketing e newsletters; games, conteúdo de entretenimento e aplicativos móveis, desenvolvidos com a marca da organização. A gratuita é aquela em que os ativos digitais com a marca da empresa são gerados e ganhos de modo orgânico na internet; é algo como, por exemplo, estar incluído nos resultados de pesquisa orgânica em sites de busca, bem como aparecer nas conversas nas redes sociais. Por fim, a presença paga é aquela em que os ativos digitais com a marca da empresa são comprados, como, por exemplo, anúncios em sites, links patrocinados e outros. $\mathrm{O}$ aspeto central da estratégia de presença digital reside na determinação e distribuição de esforços entre a presença paga, própria e gratuita.

A presença digital deve seguir a perspetiva do posicionamento de marca estabelecido pela organização. Inicialmente, para construir estratégias de marketing em redes sociais - SMM, como Facebook, Youtube e outras, é fundamental a elaboração de um plano de marketing e, após, selecionar as mídias capazes de satisfazer os objetivos de marketing traçados. Sendo assim, as estratégias em redes sociais iniciam pelo desenvolvimento do plano de marketing com a definição dos objetivos, do público-alvo, da análise de ambientes, dos produtos e outros. Para as estratégias em rede social, deve-se conhecer bem a plataforma da rede, seu público e seus atributos.

Os ambientes de redes sociais podem ser classificados basicamente a partir de duas perspetivas principais que norteiam as estratégias de marketing, que são a viralização e o poder analítico. A viralização diz respeito à capacidade do ambiente de alcançar e impactar um grande número de pessoas. Já o poder analítico está relacionado à capacidade deste em proporcionar relevância e credibilidade, que só são possíveis em ambientes que favoreçam ricas discussões e análises. Nesse sentido, um plano de marketing pode exigir um ambiente mais viral ou analítico, para alcançar um resultado positivo em suas estratégias.

O SMM - Social Media Marketing ou marketing em redes sociais - é o trabalho de promoção de website-produto-marca nas redes e mídias sociais com o intuito de atrair links e 
internautas para o site-produto-marca. SMM, explica Gabriel (2010), relaciona todas as ações internas (on-page) e externas (off-page) ao site com esse intento. Denomina-se SMO (Social Media Optimization) as ações de SMM internas do site, utilizadas para otimizar o website, para que ele se torne conhecido e seja divulgado pelos visitantes do site em mídias sociais e comunidades online. Das ações de SMO, podem fazer parte qualquer ação realizada on-page, tais como a melhoria do design e a usabilidade. Já as ações off-page de SMM são postas em prática fora do website, tendo como interesse as redes sociais. Nesse caso, são usadas técnicas para a criação e distribuição de conteúdos através das mídias sociais na forma de marketing viral WOMM (Word of Mouth Marketing).

Já o marketing de busca utiliza as plataformas de sites de busca de modo estratégico, para atingir os objetivos traçados para o marketing. Os resultados apresentados pelos sites de busca são de duas categoriais, as que se originam do processo natural de seleção dos sites, o que é definido como busca orgânica, e os resultados de busca paga. Os resultados da busca orgânica são derivados da análise que os buscadores fazem, considerando a relevância dos sites e a palavra-chave de busca. Os resultados de busca paga, argumenta Gabriel (2010), são disponibilizados na página de resultados de busca, a partir dos seguintes critérios: palavrachave procurada, relevância e aspeto mais importante, que é o valor oferecido pelo anunciante pelo clique. Esse link, ao ser clicado pelo usuário do site de busca, produz um custo para o proprietário do anúncio. Esse tipo de resultado é denominado link patrocinado ou busca paga.

SEM - Search Engine Marketing ou Marketing de busca é a técnica de utilização de sites de busca para promoção de websites, buscando com isso o aumento do tráfego de visitantes, da fidelidade e, como aspeto principal, do retorno financeiro. SEM é relativo às ações internas, on-page, e externas, off-page, relacionadas ao site com esse objetivo. A parte do SEM relativa às técnicas de otimização interna do website é denominada SEO, Search Engine Optimization. SEM inclui técnicas com ações de relações públicas e links patrocinados e também o processo de SEO de otimização on-page.

As estratégias de SEM podem ser off-page e on-page. As estratégias de SEM off-page podem ser realizadas com links patrocinados, WOMM, SMM e SMO. WOMM - Word of Mouth Marketing, SMM Social Media Marketing e SMO - Social Media Optimization são estratégias de otimização de presença em redes sociais. Outras estratégias de SEM off-page são a construção de links patrocinados, o que é feito com empresas parceiras que fazem a recomendação do website. Os programas afiliados são outra forma de conseguir links para o 
website, enquanto press releases também ajudam a obter links. Links baits ou iscas de links é a técnica que agiliza a criação de algo no website que naturalmente atrai links. Para isso, a "isca" (bait) necessita ser comentada em fóruns, colocada em blogs, levando as pessoas a construírem links para a empresa a partir de seus websites. SEO - Search Engine Optimization, otimização on-page é a area do SEM que concentra as técnicas relacionadas à manipulação do conteúdo, tais como código e outros, com o objetivo de melhorar o posicionamento na busca orgânica.

As ações de marketing trabalham na aquisição do público-alvo, enquanto as landing pages têm o encargo da conversão do público-alvo, o que significa persuadi-lo a realizar as ações planejadas. A landing page é a página que surge quando alguém clica em um anúncio, link de buscadores orgânicos ou patrocinados, ou um link em um e-mail marketing. A landing page deverá apresentar um conteúdo que esteja relacionado com o anúncio ou link clicado.

Igualmente importante é o e-mail marketing, definido por Sant'Anna et al (2009) como uma forma de marketing direto que utiliza o e-mail para realizar a comunicação de mensagens para um determinado público. Já o Mobile marketing, conforme Gabriel (2010), consiste nas ações de marketing efetivadas através de dispositivos móveis.

\section{METODOLOGIA}

Para analisar as estratégias de marketing aplicadas às plataformas digitais, com um estudo de caso, realiza-se a revisão da literatura acerca das estratégias de marketing e das plataformas digitais. Na sequência, apresentam-se dados sobre as aplicações de estratégias mercadológicas em plataformas digitais em uma grande empresa no Brasil, as Lojas Renner, a fim de explorar o referencial teórico revisado. Após, analisa-se a prática dessa empresa, para identificar suas aplicações em consonância (ou não) com os preceitos teóricos revisados.

A pesquisa será de cunho qualitativo, de modo que "tem o ambiente como fonte direta de dados" (Prodanov; Freitas, 2009, p. 81), neste caso, as Lojas Renner. O objetivo teórico é desenvolver um referencial analítico a partir do estudo da teoria sobre marketing, internet e plataformas digitais; e o objetivo operacional consiste em expor a prática dessa estratégia a partir da observação das ações das Lojas Renner em plataformas digitais.

Este estudo é uma pesquisa aplicada, que procura desenvolver conhecimentos para aplicação prática, ao observar as estratégias de marketing e de presença digital, definidas pelo 
planejamento de marketing das Lojas Renner. Constitui, assim, um estudo de caso, que "é um tipo de pesquisa qualitativa, entendido como uma categoria de investigação que tem como objeto o estudo de uma unidade de forma aprofundada, podendo tratar-se de um sujeito, de um grupo de pessoas, de uma comunidade etc..” (Prodanov; Freitas, 2009, p. 66). Já Yin (2009) define estudo de caso como pesquisa empírica que investiga um fenômeno contemporâneo em seu contexto da vida real, especificamente quando os limites entre o fenômeno e contexto não estão claramente definidos. Neste estudo, então, a investigação centra-se nas estratégias de marketing das Lojas Renner em plataformas digitais.

\section{ESTUDO DE CASO - LOJAS RENNER}

Foi a partir do ano de 1965 que as Lojas Renner tornaram-se uma empresa independente. Até então, a organização era parte do grupo A. J. Renner, indústria fabril com sede em Porto Alegre (RS). Em 1965, o grupo A. J. Renner optou por constituir a companhia Lojas Renner S.A. Na década de 1990, passou a operar no formato de loja de departamentos, especializando-se em moda, e também expandiu suas operações para outros Estados. Em 1998, já haviam sido inauguradas 13 novas lojas, totalizando 21 unidades.

Em dezembro de 1998, a J. C. Penney Brazil, Inc., subsidiária de uma rede de lojas de departamentos dos EUA, adquiriu o controle acionário da Companhia. Em 2006, tem início a atuação no Nordeste e, no decorrer do ano, foram inauguradas ainda 15 novas unidades, e a Companhia alcançou o número de 81 lojas. Em 2007, a Renner chegou à Região Norte, com a abertura de uma loja no estado do Amazonas.

Atualmente, conforme informações divulgadas pela empresa, as Lojas Renner seriam a segunda maior rede de lojas de departamentos de vestuário no Brasil, sendo que das 102 lojas existentes, 95 estão instaladas em Shopping Centers e 7 em pontos centrais de cidades, nas regiões Sul, Sudeste, Centro-Oeste, Norte e Nordeste do país.

As Lojas Renner realizam ações de marketing com o uso de meios convencionais e de plataformas digitais. Este estudo procura elucidar, pois, quais são as estratégias de marketing desenvolvidas pelas Lojas Renner, particularmente as estratégias aplicadas nas plataformas digitais.

Como destacado anteriormente, a estratégia de presença digital é que desenvolve os pontos de contato entre o público-alvo e a marca no ambiente digital, no caso das Lojas Renner, 
mulheres na faixa de consumo média e média alta. A presença digital é o estabelecimento das marcas no meio digital. Os conteúdos digitais geram a representação que concebe a presença digital (Gabriel, 2010).

Em sua estratégia de presença digital, o departamento de marketing das Lojas Renner decidiu centrar, até o momento, suas ações nas seguintes plataformas digitais: website (Figura 1), página no Twitter (Figura 2), no Facebook (Figura 3), no YouTube (Figura 4), no Pinterest (Figura 6), no Instagram (Figura 7) e em seu Blog (Figura 5). A presença digital define os pontos de contato do público com a marca Renner, que utiliza as seguintes plataformas na presença digital própria: website, blog, Perfis no You Tube, Twitter, Facebook, Pinterest, Instagram e aplicativos. Quanto à presença digital paga, a marca Renner utiliza links patrocinados no Google e no Ask.

Quanto a aplicativos, a Renner preparou uma ação com o uso de um programa, voltada para o Dia dos Namorados, conforme site da Revista Exame1. A empresa desenvolveu um aplicativo para o Facebook, com uma roleta que escolhe determinado tipo de beijo a ser enviado para um contato da lista do internauta. A ação de marketing contemplou também anúncio em revista, catálogo, material de ponto de venda e filme publicitário. O Mobile marketing foi utilizado no Dia dos Pais, data para a qual a Renner preparou uma ação na loja do Shopping Light, em São Paulo, onde, ao entrar na loja, o consumidor era convidado a ativar o bluetooth do seu celular com o objetivo de receber as promoções preparadas para a data comemorativa.

Plataformas digitais utilizadas pelas Lojas Renner são as seguintes:

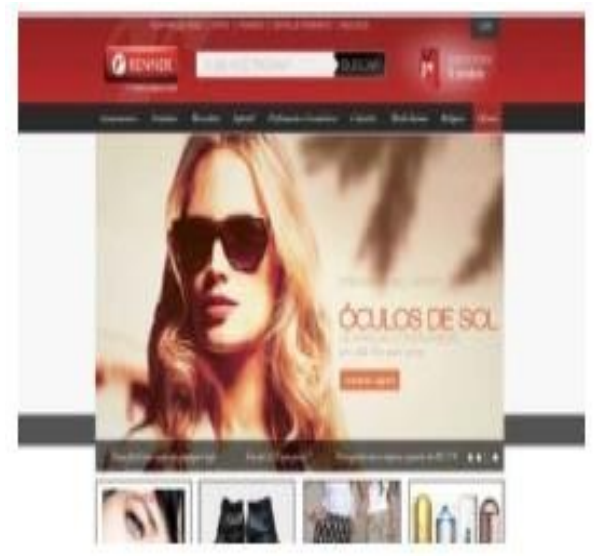

Figura 1: Site Lojas Renner

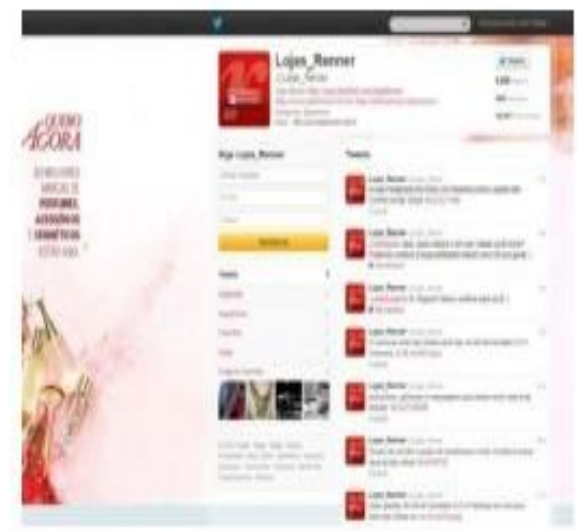

Figura 2: página Lojas Renner no Twitter 


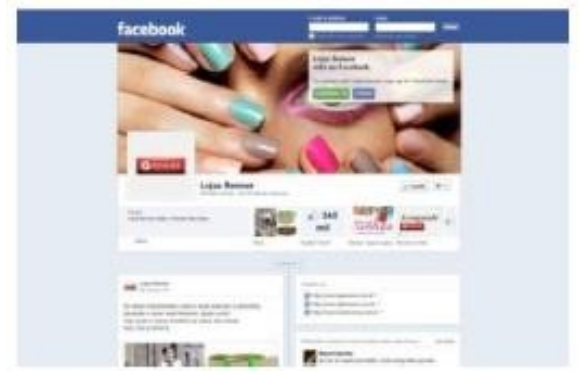

Figura 3: Página Renner no Facebook

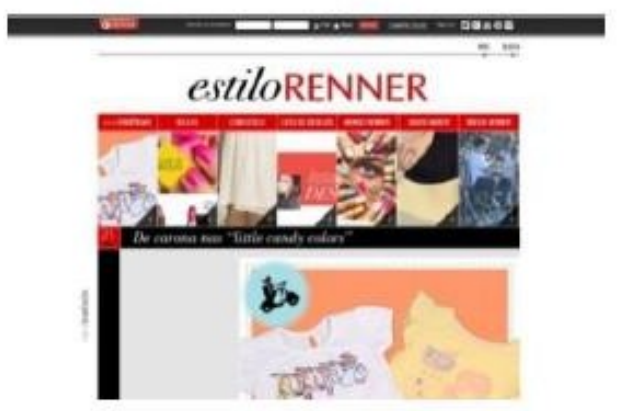

Figura 5: Blog Renner

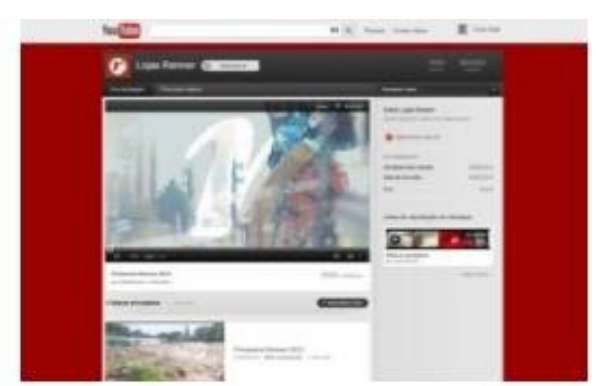

Figura 4: página Renner no You Tube

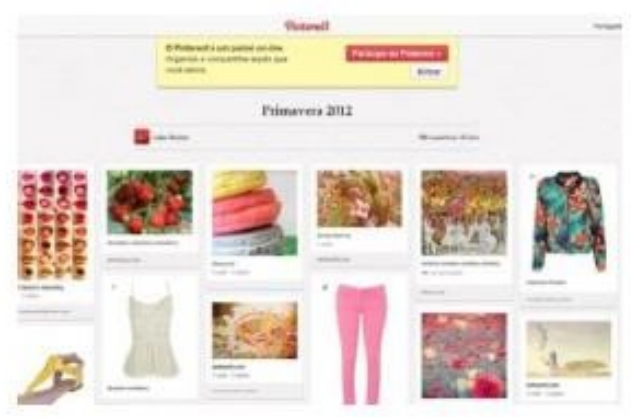

Figura 6: página Renner no Pinterest

Um dos pontos de contato da Renner com seu público em sua estratégia de presença digital é o website da empresa, o qual se caracteriza como sendo presença própria. A Renner possui uma loja virtual, onde é possível realizar a compra de vários produtos de moda masculina, feminina ou infantil, perfumaria, calçados e outros. O site é uma loja de departamentos virtual. O site apresenta links para as plataformas de redes sociais, o que possibilita ao internauta fácil acesso aos outros pontos de contato com a marca Renner no âmbito digital.

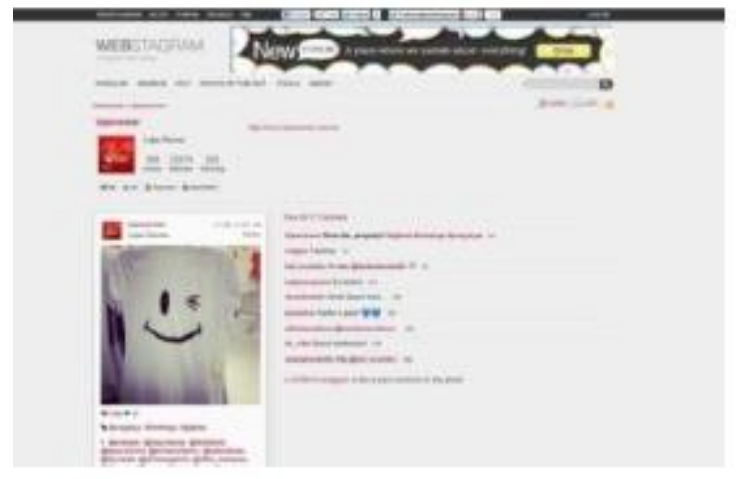

Figura 7: página Renner no Webinstagram 


\section{E3, Revista de Economia, na CPLP}

Em suas ações de marketing, que têm por função a aquisição de público-alvo, as Lojas Renner utilizam landing pages. No caso, a landing page (Figura 8) das Lojas Renner é acessada através de links, em peças de e-mail marketing e de links nos resultados de busca orgânica e paga em sites como o Google e Ask. Por meio da landing page das Lojas Renner, o internauta entra na loja virtual da marca, onde acessa lançamentos por departamentos, ofertas, promoções para datas especiais como o Dia da Criança, como se vê no exemplo a seguir. A landin page oferece vários calls to action - incentivos para agir - como chamadas para promoção de roupas femininas, convite para conhecer perfumes, promoções para o Dia da Criança, para aproveitar grandes descontos e outros.

O marketing de relacionamento online tem três objetivos básicos: a aquisição, conversão e a retenção. A meta da conversão, que é a ação esperada da parte do visitante; na landing page das Lojas Renner, é a conversão de receita, pois a venda é o objetivo.

E-mail marketing que conduz à landing page (Figura 9):

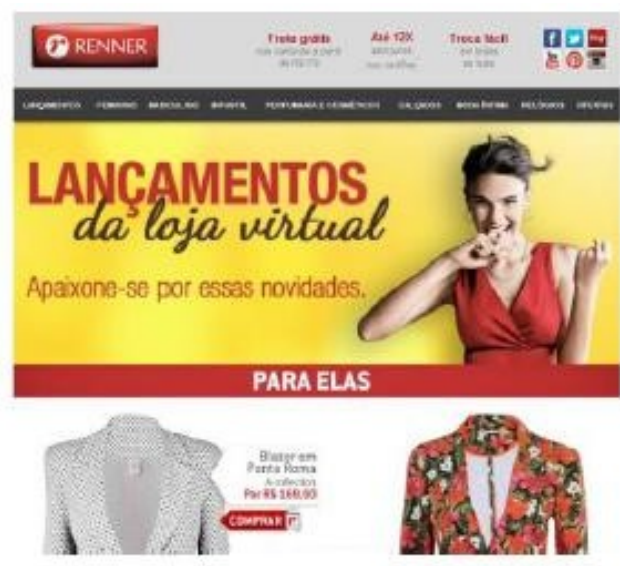

Figura 8: e-mail marketing Renner Figura

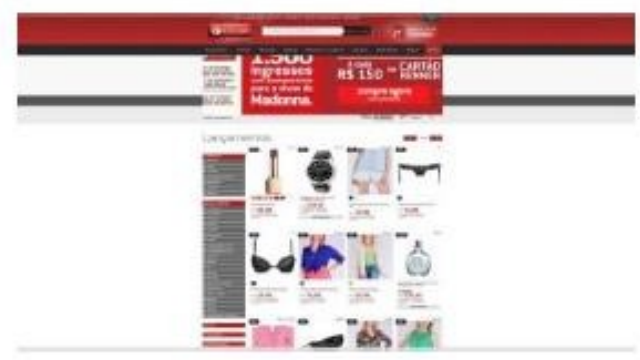

Figura 9: landing page Renner

As ações de marketing das lojas Renner incluem estratégias de SEM off-page, com o uso de links patrocinados no Google e no Ask, o que pode ser visto no primeiro resultado que aparece na página de busca na foto a seguir.

Para a busca dos termos "loja moda feminina", obtêm-se no Google (Figura 10), nos links patrocinados, resultado em que aparece a Lojas Renner. No Ask (Figura 11), o termo de pesquisa que fez aparecer o link patrocinado foi o próprio nome da loja. É preciso considerar que o critério mais adequado para utilização das estratégias de SEM Off-page é antes proceder à otimização do site, para que ele venha a ocupar uma boa posição na busca orgânica, mas quando a otimização que proporciona uma boa posição na busca natural 
chegar ao seu limite, deve-se proceder ao uso de links patrocinados, como fez a Renner, de forma a atingir os objetivos de marketing.

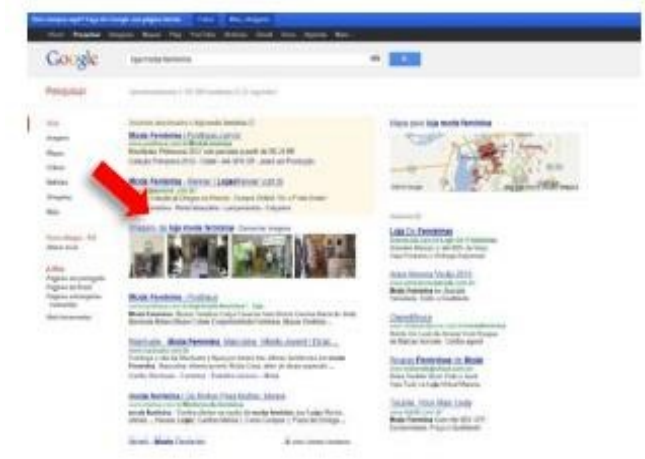

Figura 10: resultado da busca no Google

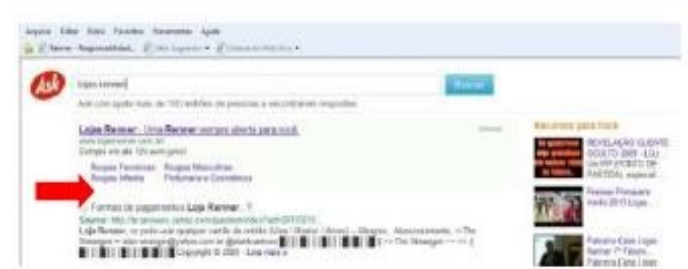

Figura 11: resultado da busca no Ask

As Lojas Renner agilizam também o envio de mensagens por e-mail marketing, realizando conexões de comunicação com seu banco de dados, pois dessa forma essa ferramenta torna possível a mensuração das atividades das pessoas que recebem as mensagens, oportuniza o rastreamento e a continuidade de ações que produzam relacionamento. $\mathrm{O}$ e-mail marketing apresenta grande capacidade de viralização, divulgando promoções, descontos e outras informações.

A figura a seguir é uma amostra do modelo de formulário (Figura 13) disponível no site, no blog e no Twitter, para o cliente solicitar o envio de e-mail marketing, o que demonstra que a empresa agiliza o envio de mensagens autorizadas para essa prática. A seguir, e-mail marketing (Figura 12) das Lojas Renner, para divulgar a mudança do cartão da loja e o Clube de Vantagens. 


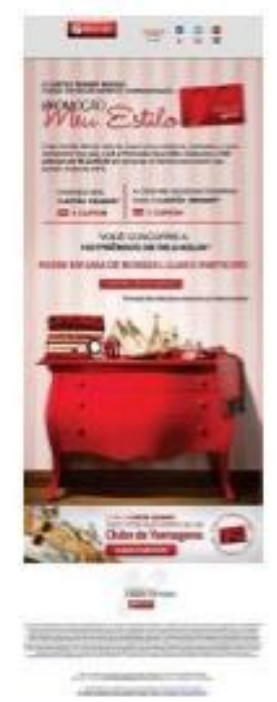

Figura 12: e-mail marketing Renner Figura

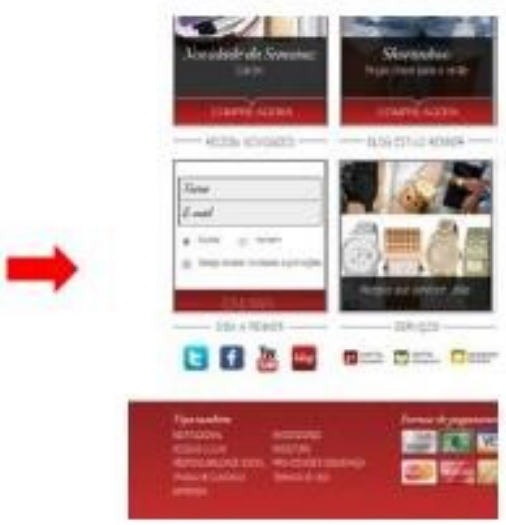

13: detalhe site Renner

Pode-se observar que a ação de e-mail marketing desenvolvida pela Renner tem o objetivo de ser continuada no site da empresa, pois a peça apresenta links que conduzem a uma página na web, que é uma landing page (Figura 14), ou seja, uma continuação da mensagem do e-mail marketing, que trata do Clube de Vantagens Renner, como se pode observar na imagem a seguir.

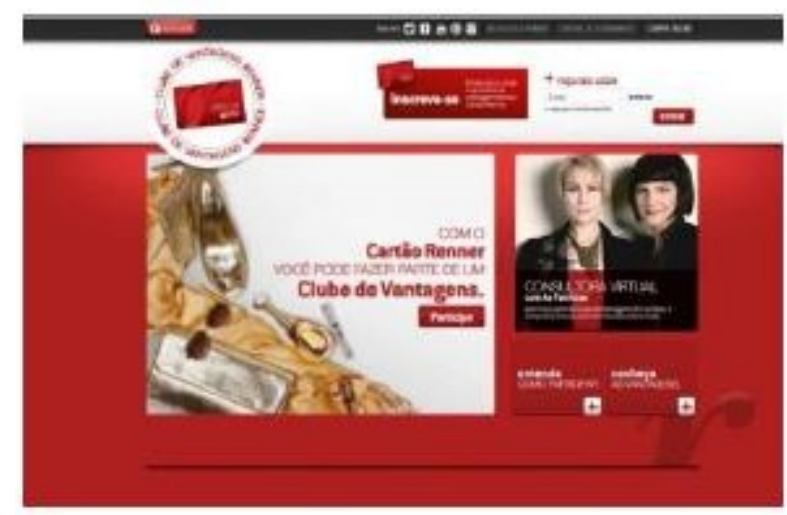

Figura 14: landing page Clube de vantagens

O e-mail marketing da Renner apresenta links para as suas páginas no Facebook (Figura 15), Twitter (Figura 18), blog da empresa (Figura 20), YouTube, Pinterest (Figura 21), que é um painel digital para a postagem de conteúdos, e WebStagram (Figura 19), visualizador web do aplicativo Instagram. O WebStagram é um site para postagem e compartilhamento de imagens, em que a Renner tem várias fotos postadas, as quais recebem comentários dos internautas. As ações em redes sociais são igualmente importantes nas estratégias de 


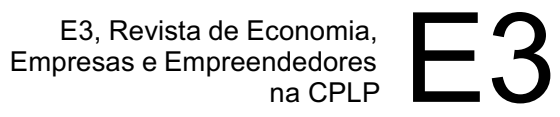

marketing das Lojas Renner. O marketing da loja propícia experiências que buscam o engajamento e a participação do consumidor. Isso pode ser observado na estratégia desenvolvida nas redes sociais, que conquista a participação dos internautas que postam comentários sobre o conteúdo divulgado pela Loja. No conteúdo disponibilizado pela Loja Renner, incluem-se dicas, sugestões e publicidade sobre moda, além de promoções. $\mathrm{Na}$ página das Lojas Renner no Facebook, pode-se observar que a loja consegue construir um envolvimento com o público-alvo, levando as pessoas a postar comentários (Figura 15). É comum que o conteúdo postado pela loja procure remeter o internauta ao blog da empresa.

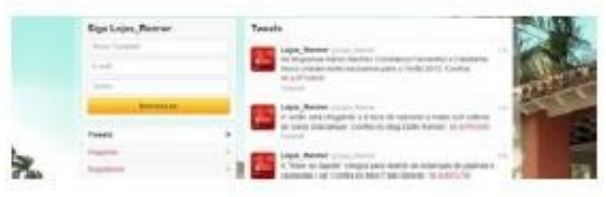

Figura 15: posts no Twitter

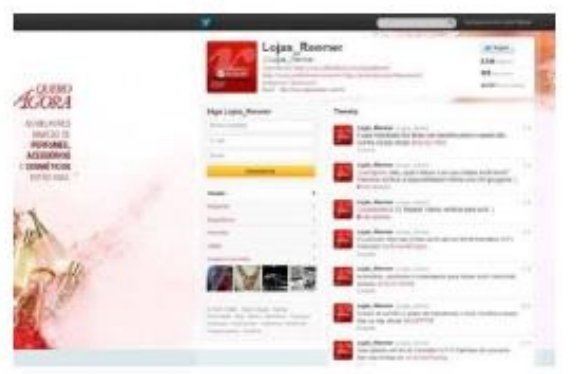

Figura 17: página no Twitter

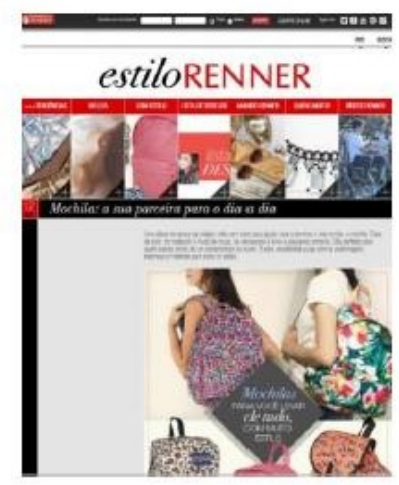

Figura 19: Blog Lojas Renner

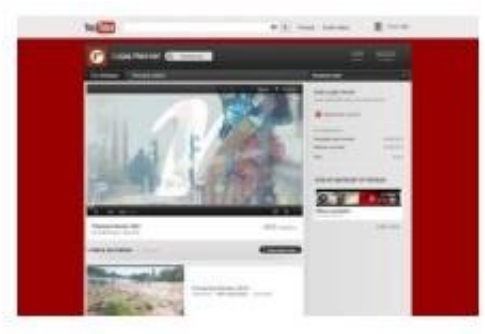

Figura 16: página da Renner no YouTube

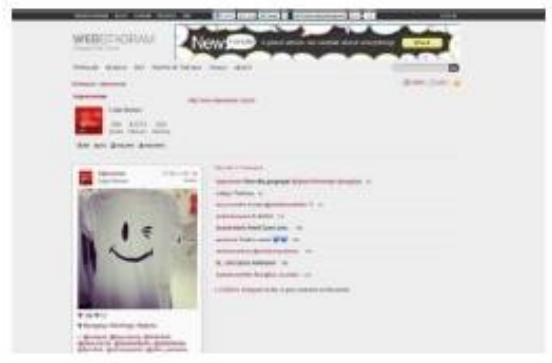

Figura 18: página Renner no Webstagram

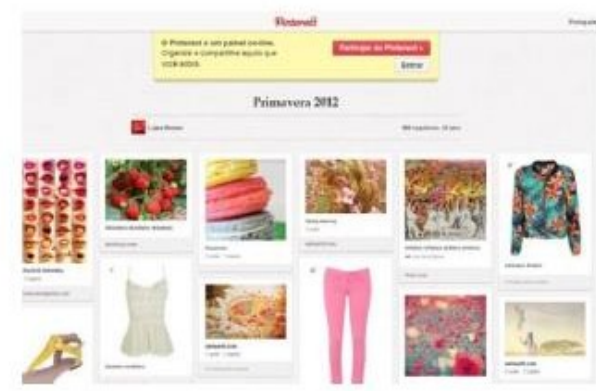

Figura 20: Pinterest 


\section{CONSIDERAÇÕES FINAIS}

na CPLP

As plataformas digitais são um suporte fundamental para as estratégias de marketing, pois possibilitam uma relação mais próxima com o consumidor. É consenso entre os teóricos que o objetivo central do marketing é entender os desejos e as necessidades dos consumidores de forma a atendê-los, pois a internet, entre outras coisas, possibilita acompanhar as manifestações do consumidor, o que dá uma boa amostra do que este deseja.

Para a administração do marketing das Lojas Renner, a internet pode ser uma ferramenta de captação, manutenção e fidelização de clientes. Após a seleção dos mercados-alvo e com o uso de plataformas digitais, a organização pode, então, comunicar um valor superior para o cliente por meio de suas ações.

As Lojas Renner, ao que parece, utilizam três canais de marketing como forma de chegar ao mercado. Nesse sentido, os meios de comunicação são um dos canais, entre as quais estão as plataformas digitais - site, blogs, páginas em redes sociais da empresa -, que agilizam a transmissão e a receção de mensagens, garantindo a interação entre o cliente e a organização. Outros canais são os de venda, dos quais fazem parte suas lojas físicas e o site de e-comerce. Além disso, existem os canais de relacionamento, que incluem também as plataformas digitais, como sites, blogs, e-mail marketing e páginas em sites de redes sociais, com os quais o cliente da loja consegue comprar, se informar e se relacionar com a Renner.

As estratégias em plataformas digitais ampliam o campo de atuação do marketing, que, além das plataformas "tradicionais", passa a contar com a internet e dispositivos digitais para desenvolver suas ações. Os benefícios para as empresas que utilizam a internet em suas estratégias de marketing podem ser grandes, considerando-se a abrangência da rede, que é mundial, e o interesse que esta desperta em seus usuários - em grande parte, pessoas muito interessadas nas novidades propiciadas pela rede.

Mas por este trabalho pode-se observar também a necessidade de as organizações conhecerem profundamente as ferramentas utilizadas em suas estratégias de presença digital.

As empresas também precisam refletir sobre o efetivo resultado que poderão alcançar com suas ações na web, de forma a avaliarem com cautela o que lhes trará melhor resultado, se estratégias em plataformas e tecnologias digitais ou em outros meios, suportes ou lugares, ou ainda uma combinação do digital e do tradicional. A internet pode ser muito adequada para algumas empresas desenvolverem suas estratégias e para outras não, pois é preciso considerar 
os objetivos que se quer atingir, o público almejado, ou seja, elaborar o planejamento de marketing, para então decidir o encaminhamento das ações. As Lojas Renner parecem fazer isso adequadamente, pois se observa que suas estratégias utilizam-se de plataformas e tecnologias digitais e convencionais, que geram ótimos resultados à rede varejista.

A exigência de resultados econômicos e financeiros é um fator crucial para o marketing na atualidade, sendo assim pode-se refletir sobre os benefícios que as estratégias de marketing em plataformas digitais conseguem trazer para as Lojas Renner. Como já foi citado, no ano de 2010, a empresa investiu R $\$ 5$ milhões somente no desenvolvimento de seu site de comércio eletrônico, o que é um indicativo de crédito nas ações no meio digital. E como as estratégias de marketing devem apontar os ganhos que serão alcançados, certamente as Lojas Renner acabam por ter retorno com todo o trabalho voltado para a internet.

As fases mais importantes do processo estratégico de marketing das Lojas Renner devem acontecer em pelo menos três níveis, que são: a estratégia central, que é relativa à definição das metas de marketing e do foco adequado para alcançá-las; o posicionamento competitivo que conduz à identificação do mercado-alvo - para as Lojas Renner, mulheres na faixa de consumo média e média alta -, bem como a definição de metas e a determinação do diferencial competitivo da rede de lojas. Na etapa da implementação, é posta em prática a estratégia, organizando o composto de marketing. Certamente, nessa etapa, as Lojas Renner definem sua estratégia de presença digital, escolhendo as plataformas onde desenvolverão suas ações.

A utilização de plataformas e tecnologias digitais se enquadra claramente na capacidade das organizações de lidarem com as forças do macro ambiente. Neste caso, especificamente, o fator tecnológico é relevante no relacionamento com o público-alvo das empresas, pois as mudanças organizadas a partir das novas tecnologias sempre acabam por causar grandes impactos nos diferentes ramos de atividade. Isso se deve ao fato de que as novas tecnologias são fundamentais para a comunicação e a informação entre as pessoas na sociedade atual.

\section{REFERÊNCIAS}

CATALANI, Luciane et al. E-commerce. Rio de Janeiro: editora FGV, 2006. 
COBRA, Marcos. Administração de marketing no Brasil. 3. ed. Rio de Janeiro: Elsevier: Campus, 2009.

GABRIEL, M. Marketing na era digital. Conceitos, plataformas e estratégias. São Paulo: Novatex, 2010.

KOTLER, Philip; KELLER, Kevin Lane. Administração de marketing. 12. ed. São Paulo: Pearson Prentice Hall, 2006.

LEMOS, André. Cibercultura, tecnologia e vida social na cultura contemporânea. 2. ed. Porto Alegre: Sulina, 2004.

LOJAS Renner lança vendas pela internet em 13 de outubro. Disponível em: $<$ http://www1.folha.uol.com.br/mercado/811511-lojas-renner-lanca-vendas-pela-internetem13-de-outubro.shtml>. Acesso em: 06 set. 2014.

LOJAS Renner assina contrato para compra da Camicado. Disponível em: $<$ http://portal.lojasrenner.com.br/renner/releases/releases!view.action;jsessionid=b7e 787 29e66bab46e900fa5166101150f0f2c456e3a37d233c939f943634b461.e3ePbx8Ta3qOe38Ka 3iKahuKbhv0?releaseImprensa.id=187>. Acesso em: 02 set. 2014.

MADRUGA, Roberto Pessoa et al. Administração de marketing no mundo contemporâneo. 4. ed. Rio de Janeiro: Editora FGV, 2011.

NASCIMENTO, Renata Muniz do. Lojas Renner investiu em promoção por bluetooth no dia dos pais. Disponível em: <http://www.mobilepedia.com.br/cases/lojas-renner-investiuem-promocao-por-bluetooth-nos-dia-dos-pais> Acesso em: 02 set. 2014.

POLÍTICA de trocas e devoluções da loja virtual Renner. Disponível em: $<$ http://lojavirtual.lojasrenner.com.br/undoing/index.jsp>. Acesso em: 17 out. 2012. PRODANOV, C.; FREITAS, E. Metodologia do trabalho científico. Novo Hamburgo: Feevale, 2009. 


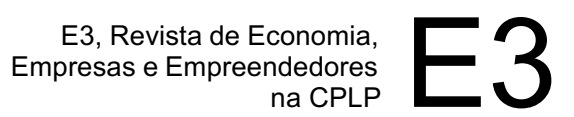

SÁ, Sylvia de. Renner cria aplicativo que distribui beijos no Facebook. Disponível em: $<$ http://exame.abril.com.br/marketing/noticias/renner-cria-aplicativo-que-distribuibeijos-no-facebook>. Acesso em: 06 set. 2014.

SANT'ANNA, A.; ROCHA Jr., I.; GARCIA, L. F. D. Propaganda: teoria, prática e técnica. São Paulo: Cengage Learning, 2009.

SIQUEIRA, Antonio Carlos Barroso de. Marketing empresarial, industrial e de serviços. Ed. rev., atual. e reform. São Paulo: Saraiva, 2005.

SOBRE a Renner -Nossa história. Disponível em:

$<$ http://portal.lojasrenner.com.br/renner/front/institucionalHistoria.jsp $>$. Acesso em: 02 set. 2012. STRAUSS, Judy; FROST, Raymond. E-marketing. 6. ed. São Paulo: Pearson, 2012.

TERRA, C. F. Blogs corporativos: modismo ou tendência? São Caetano do Sul: Editora Difusão, 2008.

YIN, Robert K. Estudo de caso: planejamento e métodos. Porto Alegre: Bookman, 2001. 